\title{
EFFICACY OF A NOVEL WATER PROPELLED, HEATING EYE MASK MASSAGER ON TEAR FILM AND OCULAR ADNEXA
}

\author{
Sònia Travé Huarte BSc \& James S. Wolffsohn BSc MBA PhD
}

\begin{abstract}
Purpose: to determine the effectiveness of the Aurai water propelled, heating Eye Massager (AEM) in managing dry eye disease and its effects on the ocular adnexa.

Methods: This was a prospective, randomised cross-over study that enrolled 15 participants (aged $25.8 \pm 5.45$ years, 5 male). Participants wore a smart watch 24 hours a day to track their sleeping cycle and heart rate for 4 weeks, using the AEM twice a day for 2 of those weeks. A cycle of 6 minutes of a controlled heat and vibration pattern in the morning and another cycle in the evening were applied with the AEM. Primary outcomes of symptomatology (Ocular Surface Disease Index (OSDI) and Symptom Assessment iN Dry Eye (SANDE)), tear film homeostasis markers (osmolarity, noninvasive breakup time (NIKBUT), tear meniscus height (TMH), lipid layer thickness and ocular staining) and safety measures (ocular redness and intraocular pressure), were assessed at baseline, after 2 weeks of AEM use and after 2 weeks of no treatment (in random-sequence). Sleeping tracking (ST) and heart rate/blood oxygen detection over these periods was also assessed.
\end{abstract}

Results: There was a significant change in OSDI score from $34.3 \pm 19.5$ at baseline to $18.8 \pm 17.5$ after treatment $(\mathrm{p}=0.001)$ and also for the SANDE $(5.7 \pm 2.4$ vs $3.7 \pm 2.1 ; \mathrm{p}$ $=0.001)$. Heart rate was not affected by treatment $(\mathrm{p}=0.956)$, nor sleep pattern $(\mathrm{p}=0.529)$, but this varied by day $(\mathrm{p}=0.001)$. Tear film homeostasis, the ocular adnexia and safety measures were not affected by treatment $(\mathrm{p}>0.05)$.

Conclusion: The Aurai water propelled Eye Massager may relieve symptoms of dry eye and its severity, but there were no detectable effects on tear stability from two weeks use.

Keywords: Dry eye, Warm compress, Symptoms, Signs, Heating devices 


\section{Introduction}

Meibomian Gland Dysfunction (MGD) has been defined as the "chronic, diffuse abnormality of the meibomian glands, commonly characterized terminal duct obstruction and/or qualitative quantitative changes in the glandular secretion. It may result in alteration of the tear film, symptoms of eye irritation, clinically apparent inflammation, and ocular surface disease"[1]. It is a subset of dry eye disease[2].

As a chronic condition that requires ongoing management, patient compliance has a significant impact on treatment efficacy [3, 4]. Many studies have assessed different efficacies of lid heating treatments and there is an established relationship between the use of eyelid warming devices and improvement of tear film stability and MGD [5]. In MGD, the meibum is altered to consist of lower levels of unsaturated fatty acids and nonpolar lipids)[6, 7], raising the melting point, causing the lipid secretions to solidify and become inspissated. The mechanism of action appears to be a clearing of the ducts through raising the temperature of the glands beyond the melting point of the altered meibum, followed by physical massaging of any remaining gland plugs [8]. Many management and therapy options had been developed to warm the lids. Such treatments include infrared devices [8,9], warm compresses [10, 11], disposable eyelid warming devices [12] and warm moist air devices [13]. The efficacy of warm compresses are presented in Table $1[10,12-24]$. Studies regarding what the most optimal temperature to melt the meibum of the glands might be suggest reasonable variability[25], perhaps greater in patients with MGD[26], affecting the efficacy of lid warming treatments.are in place $[27,28]$. Massaging in general has many health benefits and few known risks, so could massage of the eyelids and adnexia benefit sleep or blood circulation?[29] Hence, new approaches to lid warming and massage are of great interest to manage this chronic, debilitating condition.

The aim of this study was to investigate the efficacy of a novel water propelled eyelid warming device after 2 weeks use in patients with dry eye disease. 


\section{Methods}

This prospective, randomised cross-over trial adhered to the tenets of the Declaration of Helsinki and was given a favourable opinion by Aston University Ethics Committee and governance approval. It was registered as a clinical trial on www.researchregistry.com UIN \#5167.

Participants were required to be 18 years or older with a positive diagnosis of dry eye disease (DED) using the diagnostic criteria of TFOS DEWS II (symptoms of dry eye $\geq 13$ on the Ocular Surface Disease Index (OSDI) and at least one of the global signs/homeostasis markers)[30]. Exclusion criteria included use of contact lenses, current eyelid warming therapies, current artificial drop use, ocular pathologies (excluding blepharitis and MGD) and systemic issues such as diabetes and inflammatory conditions). Prior to commencement participants had signed the informed consent and were enrolled if eligible. Fifteen participants were (67\% female, age $25.8 \pm 5.45$ years, range $20-37$ years) recruited, based on the minimum sample size recommendation for repeated measure analysis of variance [31]. This number of participants has also been shown to be adequate to detect a clinically significant difference for the inter-group comparisons at $80 \%$ power with an alpha of $0.05[30,32]$. Data were measured from the right eye only except for osmolarity where the highest value between the eyes are recommended variables. All participants had had DED for at least 2 years

The baseline measurements, conducted in the following order, were: OSDI; Symptom Assessment iN Dry Eye (SANDE)[33]; Osmolarity, highest value from 2 eyes collected from the lower meniscus [34] using a TearLab station (TearLab Ltd, California, USA) with calibration performed every day following the manufacturer's instructions and TearLab chips were placed beside the station for humidity and temperature regulation; Ocular Hyperaemia in the nasal and temporal bulbar and limbal regions $(\mathrm{OH})$; Tear meniscus height (TMH) illuminated with infrared light, calculated from a calibrated digital image; Non-Invasive Breakup Time (NIKBUT) - average of 3 readings after two non-forceful blinks; and Lipid layer thickness (LLT) evaluated by tear film interferometry and graded as: 0 (absent), 1 (open meshwork), 2 (closed meshwork), 3 (wave), 4 (amorphous), or 5 (coloured fringes), all evaluated objectively (except LLT) using the Keratograph 5M (Oculus, Wetzlar, Germany)[35]. 
Ocular staining with fluorescein, corneal staining (CornS) was assessed by wetting a fluorescein strip with saline, shaking off the excess, and instilling it at the outer canthus. Lissamine green, conjunctival staining (ConjS), was assessed by wetting a Lissamine strip (GreenGlo, HUB Pharmaceuticals, LLC, Rancho Cucamonga, California, USA) with a single drop of saline solution, keeping the drop on the strip for 5 seconds to elude the dye, and instilling it at the outer canthus. Assessment was performed with a slit lamp and the number of punctate spots counted[30].

The Aurai Eye Massager (AEM) has an integral silicon mask which contains water which can be warmed/cooled and vibrated (Figure 1). The water-propelled massager is marketed as relaxing muscular tension around the eyes, to improve blood circulation and relaxation. All measurements were performed by the same clinician in the same order. The assessment was conducted in a room where temperature and humidity remained constant between $20-22^{\circ} \mathrm{C}$ and $30-45 \%$ respectively, to ensure that the measurements were not affected by ambient humidity. Participants spent a minimum of 10 min acclimatising to the room conditions before being tested as factors such as humidity can affect measurements [36].

Participants were required to wear a watch (IP68 Fitness Activity Tracker, Smart Watch, Teepao.com), 24h a day, which captured Heart Rate and Blood Oxygen (O2 - using red and infra-red light pulse oximetry) and sleeping time (ST - through inactivity of movement). All participants wore the watch for 4 weeks; for 2 weeks no intervention was undertaken (control condition) and for the other 2 weeks, participants were instructed to use the AEM 6 minutes twice daily, using the warm and vibration cycle as recommended in the manufacturers instructions. The AEM warms to $40^{\circ} \mathrm{C}+3 /-2^{\circ} \mathrm{C}$ within 2 minutes and remains at this temperature for the rest of the 6 minute vibration cycle. The order of the control condition and AEM treatment was randomised between participants. After each two weeks participants returned and the measures captured at baseline were repeated by a masked researcher. Participants were not masked due to the appearance of the device and the physical sensation. After returning the AEM, participants were asked how often they had used the AEM. Patient compliance was recorded (number of times the system was used during the 2 weeks). 
Heart rate, Blood Oxygen (O2) and Sleeping Time (ST) were gathered from the watch. Intraocular pressure was measured at each visit with Ocular Response Analyser (ORA) (Reichert Technologies, Germany). In addition, IOP was measures before and at minute intervals after eye massager use for 3 minutes at the end of the study to examine for any immediate pressure spikes.

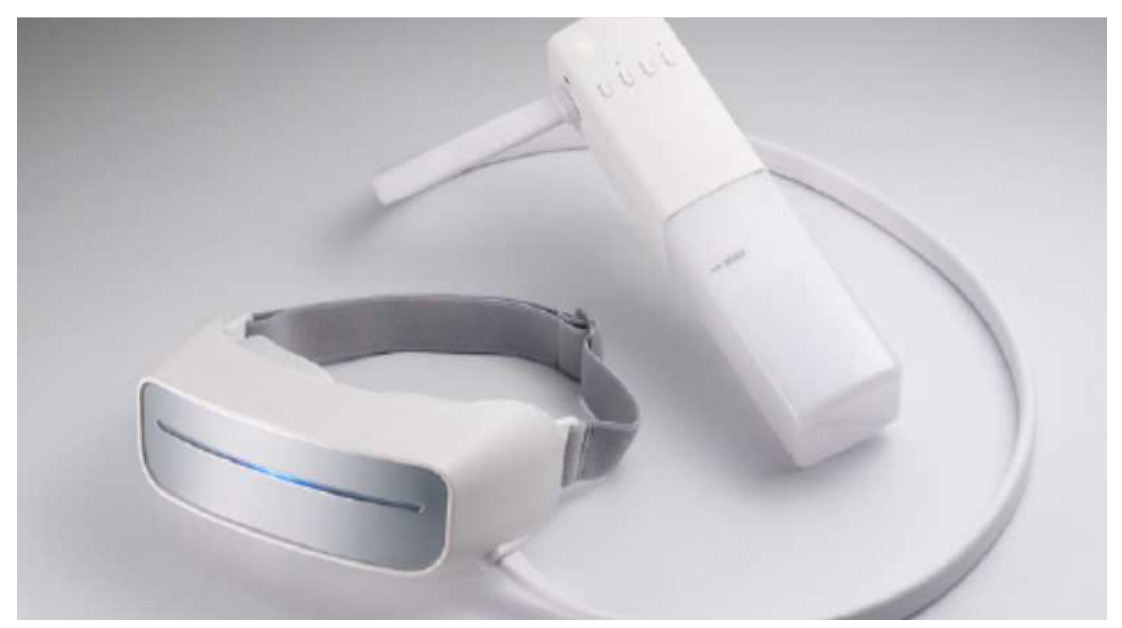

Figure 1: AURAI Mask Massager

\section{Data analysis}

Statistical analysis was performed using IBM SPSS Statistics version 25 (New York, USA). The distributions of the data was assessed using one-sample Kolmogorov-Smirnov test. Symptomology, intraocular pressure, heart rate, blood oxygen and sleeping time were found to be normally distributed and therefore analysed with a repeated measured Analysis of Variance, while the other metrics were assessed with a related sample Friedman's Analysis of Variance by Ranks. All tests were two-tailed and $p<0.05$ was considered significant. 


\section{Results}

All participants completed the study and reported good compliance (a maximum of one missed treatment). They had mild to moderate symptoms (Table 2) and had had DED for at least 2 years.

Summary statistics of clinical measurements at baseline, after 2 weeks of no treatment, and 2 weeks post-treatment are presented in Table 2. Dry eye symptoms decreased with treatment (OSDI and SANDE severity metric; $\mathrm{p}<0.001$ ). Interestingly, there was an apparent placebo effect of just wearing the fitness monitoring watch (OSDI: $\mathrm{p}=0.042$; SANDE severity; $\mathrm{p}=0.006$ ).

Table 2: Measurement Pre and post treatment. Average $\pm S D$ or median (range) of dry eye symptoms and signs at baseline, after 2 weeks of watch control, and after 2 weeks of treatment. $N=15$. SANDE = Symptom Assessment in Dry Eye (consisting of a frequency of symptoms and severity of symptoms visual analogue scale), TMH = Tear Meniscus Height, NIKBUT = Non-Invasive Keratometric Break-Up Time, LLT $=$ Lipid Layer Thickness, IOP = Intra Ocular Pressure, , O2 = Blood Oxygen, $S T=$ Sleeping Time

\begin{tabular}{|c|c|c|c|c|}
\hline & Baseline & $\begin{array}{ll}\text { Post } & \text { control } \\
\text { period } & \\
\end{array}$ & Post AEM & $\begin{array}{l}\text { Significance } \\
\text { (p-value) }\end{array}$ \\
\hline OSDI & $34.3 \pm 19.5$ & $26.5 \pm 19.8$ & $18.8 \pm 17.5$ & 0.001 \\
\hline SANDE Frequency & $4.05 \pm 2.20$ & $4.03 \pm 2.46$ & $2.55 \pm 1.61$ & 0.262 \\
\hline SANDE Severity & $5.70 \pm 2.43$ & $4.35 \pm 2.40$ & $3.65 \pm 2.12$ & 0.001 \\
\hline $\begin{array}{l}\text { Osmolarity } \\
(\mathrm{mOsm} / \mathrm{l})\end{array}$ & $293(284-348)$ & $291(285-312)$ & $291(280-307)$ & 0.888 \\
\hline $\begin{array}{l}\text { Bulbar redness } \\
\text { temporal (grade) }\end{array}$ & $0.6(0.0-1.1)$ & $0.5(0.3-1.5)$ & $0.6(0.4-0.8)$ & 0.534 \\
\hline $\begin{array}{l}\text { Bulbar redness } \\
\text { nasal (grade) }\end{array}$ & $0.6(0.4-1.7)$ & $0.6(0.3-2.1)$ & $0.5(0.0-1.7)$ & 0.775 \\
\hline $\begin{array}{l}\text { Limbal redness } \\
\text { temporal (grade) }\end{array}$ & $0.3(0.0-1.1)$ & $0.3(0.0-1.4)$ & $0.3(0.2-1.7)$ & 0.971 \\
\hline $\begin{array}{l}\text { Limbal redness } \\
\text { nasal (grade) }\end{array}$ & $0.4(0.2-0.7)$ & $0.4(0.2-2.0)$ & $0.3(0.2-0.6)$ & 0.472 \\
\hline TMH (mm) & $0.22(0.12-0.63)$ & $0.24(0.11-0.45)$ & $0.23(0.13-0.42)$ & 0.247 \\
\hline NIKBUT (s) & $6.3(4.2-10.8)$ & $5.4(3.8-13.7)$ & $5.3(1.0-12.7)$ & 0.430 \\
\hline LLT (grade) & $2.0(1.0-3.0)$ & $2.0(1.0-3.0)$ & $2.0(1.0-3.0)$ & 0.975 \\
\hline $\begin{array}{l}\text { Corneal staining } \\
\text { (grade) }\end{array}$ & $0.0(0.0-3.0)$ & $0.0(0.0-3.0)$ & $0.0(0.0-1.0)$ & 0.949 \\
\hline $\begin{array}{l}\text { Conjunctival } \\
\text { staining (grade) }\end{array}$ & $1.0(0.0-3.0)$ & $1.0(0.0-3.0)$ & $1.0(0.0-3.0)$ & 0.575 \\
\hline $\begin{array}{l}\text { Lid margin staining } \\
\text { (grade) }\end{array}$ & $1.0(0.0-3.0)$ & $1.0(0.0-3.0)$ & $1.0(0.0-3.0)$ & 0.298 \\
\hline
\end{tabular}




\begin{tabular}{lllll} 
IOP $(\mathrm{mmHg})$ & $13.91 \pm 1.89$ & $13.29 \pm 2.02$ & $13.83 \pm 2.59$ & 0.349 \\
$\begin{array}{l}\text { Heart rate } \\
\text { per minute) }\end{array}$ & & $81.33 \pm 9.16$ & $81.10 \pm 9.84$ & 0.828 \\
O2 $(\%)$ & N/A & $98.87 \pm 36.11$ & $97.37 \pm 3.69$ & 0.268 \\
ST (hours) & N/A & $6.94 \pm 1.89$ & $7.38 \pm 1.30$ & 0.529 \\
\hline
\end{tabular}

Intraocular pressure did increase immediately after use of the AEM $(\mathrm{F}=4.113, \mathrm{p}=0.017)$ by $1.5 \pm 2.0 \mathrm{mmHg}$, but this reduced rapidly (difference from baseline: 2 minutes, $+1.3 \pm$ $2.3 \mathrm{mmHg} ; 3$ minutes, $-0.49 \pm 2.3 \mathrm{mmHg}$ ). 


\section{Discussion}

This study investigated the efficacy of a novel water propelled eyelid automated warming device after 2 weeks use in patients with dry eye disease. The OSDI scores at baseline ranged from 13 to 66 indicating mild to moderate DED severity. Two weeks use, twice a day, has previously been shown to be an effective duration of treatment of the meibomian glands to observe improvements in symptoms and signs such as tear stability, lipid layer thickness and meibomian gland expressability, but generally not ocular surface staining or meibomian gland drop-out (Table 1)[10, 12-24]. Several studies have shown immediate patient benefit from even a single session of eyelid warming [10, 20, 37] including in non-dry eye individuals $[4,11]$, making this an attractive treatment option.

There was a clear reduction on symptoms having used the AEM device for 2 weeks. The improvement of 15.5 points on the OSDI is comparable with previously reported warm compress studies (Table 1). Comfort was the only subjective measure and in the repeatedmeasures design it also appeared to improve in the period when there was no treatment (the control condition), hence a possible 'placebo' effect of being monitored. However, when just the participants who were randomised to have the no treatment period monitoring before using the AEM device are considered, no improvement in symptoms was seen (the difference in symptomatology was only $-0.4 \pm 6.5$ for the OSDI and $0.1 \pm 1.6$ for the SANDE Severity score [minus indicates worsening symptoms]); this suggests that the improvement in symptoms following use of the AEM was a real and sustained effect, as the participant randomised to use the AEM device first followed by 2 weeks of no treatment had little reason to believe that the benefit in symptomatology would occur even when assessed two week after last using the device. Compliance was reported as being good by all participants which may have been aided by the reduction in symptoms resulting from the AEM use.

Unlike previous studies (Table 1), no improvement was seen in ocular surface signs. It is well known that the signs \& symptoms of dry eye disease do not correlate well [38], however the finding does not allow the mechanism of the improvement in symptoms to be explained. Perhaps the massaging of the skin around the eyes might be contributing to the benefit on symptomatology [29]. 
Previous studies had not looked at other possible general health benefits such as improved lower levels of stress as indicated by heart rate, blood oxygen and sleep duration (Table 1). Most participants, unprompted, reported a feeling of being relaxed after the use of the mask, but the number of hours to sleep prior or after the use of AEM did not change statistically. In this study, no difference was seen in these possible general health benefits, but that might be because of the short-term use of the eye mask. Future longer duration studies could examine these potential general health benefits more in depth. It is known that rubbing the eyes can increase the IOP [39]; the lack of any change seen on this study suggests that there are no immediate or long-term safety concerns from the massaging action.

In conclusion a considerable improvement in subjective symptom severity has been shown after the use of the AEM device, sustained over at least 2 weeks, even though no improvement in clinical signs were detectable in this study. Further randomised studies with longer term use of the AEM are required to fully explore the potential benefit of novel eye warming and massaging devices.

\section{Funding:}

This research did not receive any specific grant from funding agencies in the public, commercial, or not-for-profit sectors. None of the authors have any proprietary interests relating to this research. STH was supported by Aston University research scholarship. The funding sources had no role in study design; collection, analysis and interpretation of data; the writing of the report; or the decision to submit the article for publication. Researchers are grateful to AURAI company for donating the Eye Mask Devices to the university.

\section{Acknowledgments}

None. 


\section{References}

1. Nichols, K.K., et al., The international workshop on meibomian gland dysfunction: executive summary. Invest Ophthalmol Vis Sci, 2011. 52(4): p. 1922-9.

2. Craig, J.P., et al., TFOS DEWS II Definition and Classification Report. Ocul Surf, 2017. 15(3): p. 276-283.

3. Geerling, G., et al., The international workshop on meibomian gland dysfunction: report of the subcommittee on management and treatment of meibomian gland dysfunction. Invest Ophthalmol Vis Sci, 2011. 52(4): p. 2050-64.

4. Pult, H., B.H. Riede-Pult, and C. Purslow, A Comparison of an Eyelid-Warming Device to Traditional Compress Therapy. Optometry and Vision Science, 2012. 89(7): p. E1035E1041.

5. Yeo, S., et al., Longitudinal Changes in Tear Evaporation Rates After Eyelid Warming Therapies in Meibomian Gland Dysfunction. Invest Ophthalmol Vis Sci, 2016. 57(4): p. 1974-81.

6. McCulley, J.P. and W.E. Shine, The lipid layer of tears: dependent on meibomian gland function. Exp Eye Res, 2004. 78(3): p. 361-5.

7. Mathers, W.D. and J.A. Lane, Meibomian gland lipids, evaporation, and tear film stability. Adv Exp Med Biol, 1998. 438: p. 349-60.

8. Finis, D., et al., Evaluation of Meibomian Gland Dysfunction and Local Distribution of Meibomian Gland Atrophy by Non-contact Infrared Meibography. Curr Eye Res, 2015. 40(10): p. 982-9.

9. Goto, E., et al., Treatment of non-inflamed obstructive meibomian gland dysfunction by an infrared warm compression device. Br J Ophthalmol, 2002. 86(12): p. 1403-7.

10. Bilkhu, P.S., S.A. Naroo, and J.S. Wolffsohn, Randomised masked clinical trial of the MGDRx eyebag for the treatment of meibomian gland dysfunction-related evaporative dry eye. British Journal of Ophthalmology, 2014. 98(12): p. 1707-1711.

11. Bilkhu, P.S., S.A. Naroo, and J.S. Wolffsohn, Effect of a Commercially Available Warm Compress on Eyelid Temperature and Tear Film in Healthy Eyes. Optometry and Vision Science, 2014. 91(2): p. 163-170.

12. Mori, A., et al., Disposable eyelid-warming device for the treatment of meibomian gland dysfunction. Japanese Journal of Ophthalmology, 2003. 47(6): p. 578-586.

13. Matsumoto, Y., et al., Efficacy of a new warm moist air device on tear functions of patients with simple meibomian gland dysfunction. Cornea, 2006. 25(6): p. 644-650.

14. Wang, M.T.M., et al., Randomised trial of the clinical utility of an eyelid massage device for the management of meibomian gland dysfunction. Contact Lens \& Anterior Eye, 2019. 42(6): p. 620-624.

15. Tichenor, A.A., et al., Effect of the Bruder moist heat eye compress on contact lens discomfort in contact lens wearers: An open-label randomized clinical trial. Contact Lens \& Anterior Eye, 2019. 42(6): p. 625-632.

16. Gao, Y.F., et al., Comparison of anti-inflammatory effects of intense pulsed light with tobramycin/dexamethasone plus warm compress on dry eye associated meibomian gland dysfunction. International Journal of Ophthalmology, 2019. 12(11): p. 1708-1713.

17. Murphy, O., V. O'Dwyer, and A. Lloyd-Mckernan, The Efficacy of Warm Compresses in the Treatment of Meibomian Gland Dysfunction and Demodex Folliculorum Blepharitis. Current Eye Research.

18. Badawi, D., TearCare (R) system extension study: evaluation of the safety, effectiveness, and durability through 12 months of a second TearCare $(R)$ treatment on subjects with dry eye disease. Clinical Ophthalmology, 2019. 13: p. 189-198.

19. Badawi, D., A novel system, TearCare (R), for the treatment of the signs and symptoms of dry eye disease. Clinical Ophthalmology, 2018. 12: p. 683-694.

20. Arita, R., et al., Effects of a warm compress containing menthol on the tear film in healthy subjects and dry eye patients. Scientific Reports, 2017. 7. 
21. Zhao, Y., et al., Clinical Trial of Thermal Pulsation (LipiFlow) in Meibomian Gland Dysfunction With Preteatment Meibography. Eye \& Contact Lens-Science and Clinical Practice, 2016. 42(6): p. 339-346.

22. Blackie, C.A., et al., The sustained effect (12 months) of a single-dose vectored thermal pulsation procedure for meibomian gland dysfunction and evaporative dry eye. Clinical Ophthalmology, 2016. 10: p. 1385-1395.

23. Villani, E., et al., Evaluation of a novel eyelid-warming device in meibomian gland dysfunction unresponsive to traditional warm compress treatment: an in vivo confocal study. International Ophthalmology, 2015. 35(3): p. 319-323.

24. Lane, S.S., et al., A New System, the LipiFlow, for the Treatment of Meibomian Gland Dysfunction. Cornea, 2012. 31(4): p. 396-404.

25. Bron, A.J. and J.M. Tiffany, The contribution of meibomian disease to dry eye. Ocul Surf, 2004. 2(2): p. 149-65.

26. Osgood, J.K., J.M. Dougherty, and J.P. McCulley, The role of wax and sterol esters of meibomian secretions in chronic blepharitis. Invest Ophthalmol Vis Sci, 1989. 30(9): p. 1958-61.

27. Wang, M.T., A. Gokul, and J.P. Craig, Temperature profiles of patient-applied eyelid warming therapies. Cont Lens Anterior Eye, 2015. 38(6): p. 430-4.

28. Blackie, C.A., et al., Inner eyelid surface temperature as a function of warm compress methodology. Optom Vis Sci, 2008. 85(8): p. 675-83.

29. Westman, K.F. and C. Blaisdell, Many Benefits, Little Risk: The Use of Massage in Nursing Practice. Am J Nurs, 2016. 116(1): p. 34-9; quiz 40-1.

30. Wolffsohn, J.S., et al., TFOS DEWS II Diagnostic Methodology report. Ocul Surf, 2017. 15(3): p. 539-574.

31. Armstrong, R.A., F. Eperjesi, and B. Gilmartin, The application of analysis of variance (ANOVA) to different experimental designs in optometry. Ophthalmic Physiol Opt, 2002. 22(3): p. 248-56.

32. Zhao, Y., C.L. Tan, and L. Tong, Intra-observer and inter-observer repeatability of ocular surface interferometer in measuring lipid layer thickness. BMC Ophthalmol, 2015. 15: p. 53.

33. Amparo, F., D.A. Schaumberg, and R. Dana, Comparison of Two Questionnaires for Dry Eye Symptom Assessment: The Ocular Surface Disease Index and the Symptom Assessment in Dry Eye. Ophthalmology, 2015. 122(7): p. 1498-503.

34. Gokhale, M., U. Stahl, and I. Jalbert, In situ osmometry: validation and effect of sample collection technique. Optom Vis Sci, 2013. 90(4): p. 359-65.

35. Whitcher, J.P., et al., A simplified quantitative method for assessing keratoconjunctivitis sicca from the Sjogren's Syndrome International Registry. Am J Ophthalmol, 2010. 149(3): p. 405-15.

36. Teson, M., et al., Influence of Climate on Clinical Diagnostic Dry Eye Tests: Pilot Study. Optom Vis Sci, 2015. 92(9): p. e284-9.

37. Turnbull, P.R.K., S.L. Misra, and J.P. Craig, Comparison of treatment effect across varying severities of meibomian gland dropout. Contact Lens \& Anterior Eye, 2018. 41(1): p. 8892.

38. Begley, C.G., et al., The relationship between habitual patient-reported symptoms and clinical signs among patients with dry eye of varying severity. Invest Ophthalmol Vis Sci, 2003. 44(11): p. 4753-61.

39. Liu, W.C., et al., Effects of eye rubbing and breath holding on corneal biomechanical properties and intraocular pressure. Cornea, 2011. 30(8): p. 855-60.

40. Murphy, O., V. O'Dwyer, and A. Lloyd-Mckernan, The Efficacy of Warm Compresses in the Treatment of Meibomian Gland Dysfunction and Demodex Folliculorum Blepharitis. Current Eye Research, 2020. 45(5): p. 563-575. 
Table 1: Comparison of dispensing warm compress efficacy studies. Symptom improvement reported for dry eye group from warm compress therapy. MGD meibomian gland dysfunction; IPL intense pulse light therapy; LLT lipid layer thickness; NIBUT non-invasive breakup time; TBUT fluorescein tear breakup time; MG meibomian gland; OSDI ocular surface disease index; SANDE symptom assessment in dry; SPEED standard patient evaluation of eye dryness; DEQS dry eye-related quality-of-life score; TMH tear meniscus height; IOP intraocular pressure.

\begin{tabular}{|c|c|c|c|c|c|c|c|c|}
\hline Study & Participants & $\begin{array}{l}\text { Warm } \\
\text { Compress }\end{array}$ & Comparison & Duration & Sign Improvements & $\begin{array}{l}\text { Symptom } \\
\text { Improvement } \\
\text { with warm } \\
\text { compress }\end{array}$ & $\begin{array}{l}\text { Measures } \\
\text { Unchanged }\end{array}$ & Additional Comments \\
\hline $\begin{array}{l}\text { Murphy } \\
\text { et al., } \\
2020[40]\end{array}$ & 42 MGD & $\begin{array}{l}\text { MGDRx } \\
\text { EyeBag \& } \\
\text { OPTASE Moist } \\
\text { Heat Mask }\end{array}$ & Warm face cloth & $\begin{array}{l}8 \text { weeks, } 10 \mathrm{~min} \\
2 \mathrm{x} / \text { day for } 2 \\
\text { weeks }\end{array}$ & $\begin{array}{l}\text { MG quality \& expressability, } \\
\text { Demodex (OPTASE only) }\end{array}$ & $\begin{array}{l}-23.1 \text { from } 39.8 \\
\text { OSDI Eyebag } \\
-12.5 \text { from } 39.0 \\
\text { OPTASE mask }\end{array}$ & $\begin{array}{l}\text { Osmolarity, } \\
\text { NIBUT, } \\
\text { Schirmer I test }\end{array}$ & $\begin{array}{l}\text { Face cloth cohort OSDI } \\
\text { baseline was } 24 \text { vs } 40 \text { in } \\
\text { commercial compress groups }\end{array}$ \\
\hline $\begin{array}{l}\text { Wang et } \\
\text { al., } 2019 \\
{[14]}\end{array}$ & 20 dry eye & $\begin{array}{l}\text { MGDRx } \\
\text { Eyebag }\end{array}$ & \begin{tabular}{l}
\multicolumn{2}{l}{ Contralateral } \\
eyelid massager \\
vs \\
massage
\end{tabular} & $\begin{array}{l}2 \text { weeks, } 10 \mathrm{~min} \text { a } \\
\text { day }\end{array}$ & LLT, NIBUT & Not measured & $\begin{array}{l}\text { Visual acuity, } \\
\text { TMH, redness, } \\
\text { corneal staining, } \\
\text { MG dropout }\end{array}$ & $\begin{array}{l}\text { Measures } 15 \text { minutes post } \\
\text { treatment }\end{array}$ \\
\hline $\begin{array}{l}\text { Tichenor } \\
\text { et al., } \\
2019[15]\end{array}$ & $\begin{array}{l}51 \text { contact } \\
\text { lens dry eye }\end{array}$ & $\begin{array}{l}\text { Bruder moist } \\
\text { heat compress }\end{array}$ & $\begin{array}{lr}\begin{array}{l}\text { Single vs } \\
\text { applications }\end{array} & \text { vs } \\
\text { washcloth } & \\
\end{array}$ & $\begin{array}{l}4 \text { weeks, } 10 \mathrm{~min} \\
\text { applications }\end{array}$ & $\begin{array}{l}\text { Comfortable wear time and MG } \\
\text { expressability with Bruder mask } \\
\text { regardless of frequency of use }\end{array}$ & $\begin{array}{l}-8.9 \text { from } 22.9 \\
\text { OSDI } 1 \mathrm{x} / \text { day, }- \\
16.3 \text { from } 33.8 \\
2 \mathrm{x} / \text { day }\end{array}$ & TBUT & \\
\hline $\begin{array}{l}\text { Gao et } \\
\text { al., } 2019 \\
{[16]}\end{array}$ & 82 MGD & $\begin{array}{l}\text { Tobramycin/de } \\
\text { camethasone }+ \\
\text { warm compress }\end{array}$ & IPL & $\begin{array}{l}4 \text { weeks, } 10 \text { min } \\
\text { compress nightly }\end{array}$ & $\begin{array}{l}\text { TBUT, MG expressability (1 } \\
\text { month) and cytokines ( } 1 \text { wk) } \\
\text { with IPL }\end{array}$ & $\begin{array}{l}-16.7 \text { from } 38.1 \\
\text { OSDI }\end{array}$ & $\begin{array}{lr}\text { OSDI, } & \text { corneal } \\
\text { staining, } & \mathrm{MG} \\
\text { dropout } & \end{array}$ & $\begin{array}{l}\text { Warm compress not as good as } \\
\text { IPL } \\
\text { Both groups applied sodium } \\
\text { hyaluronate eye } \\
\text { drops } 4 x / \text { day }\end{array}$ \\
\hline $\begin{array}{l}\text { Badawi, } \\
2018 \& \text { \& } \\
2019[18, \\
19]\end{array}$ & $\begin{array}{l}24 \text { dry eye, } \\
12 \quad \text { in } \\
\text { extension }\end{array}$ & Heat mask & Tearcare system & $\begin{array}{l}4 \text { weeks, } 5 \text { min } \\
\text { daily followed up } \\
\text { after } 6 \text { months }\end{array}$ & $\begin{array}{l}\text { TBUT, MG expression, corneal } \\
\& \text { conjunctival staining with } \\
\text { Tearcare, worsening TBUT with } \\
\text { heat mask }\end{array}$ & $\begin{array}{l}-8.4 \text { from } 33.0 \\
\text { OSDI. SPEED } \\
\text { \& SANDE also } \\
\text { improved }\end{array}$ & None reported & $\begin{array}{l}\text { No changes in IOP at } 6 \text { months. } \\
\text { Tearcare retreatment at } 6 \\
\text { months boosted benefits. Sole } \\
\text { author employee of device } \\
\text { company }\end{array}$ \\
\hline $\begin{array}{l}\text { Arita et } \\
\text { al., } 2017 \\
{[20]}\end{array}$ & $\begin{array}{l}35 \text { dry eye, } \\
20 \text { controls }\end{array}$ & Heat mask & $\begin{array}{l}\text { Contralateral } \\
\text { eyelid with or } \\
\text { without menthol }\end{array}$ & $\begin{array}{l}2 \text { weeks, } 10 \mathrm{~min} \\
2 \mathrm{x} / \text { day }\end{array}$ & $\begin{array}{l}\text { MG quality improved in all } \\
\text { patients, but TMH and TBUT } \\
\text { only increased with menthol } \\
\text { mask }\end{array}$ & $\begin{array}{l}-25.5 \text { from } 49.7 \\
\text { with heat, }-17.8 \\
\text { from } 41.0 \text { with }\end{array}$ & Corneal staining & $\begin{array}{l}\text { Effects were also seen after a } \\
\text { single } 10 \text { min application }\end{array}$ \\
\hline
\end{tabular}




\begin{tabular}{|c|c|c|c|c|c|c|c|c|}
\hline & & & & & & $\begin{array}{l}\text { heat \& menthol } \\
\text { DEQS }\end{array}$ & & \\
\hline $\begin{array}{l}\text { Zhao et } \\
\text { al., } 2016 \\
{[21]}\end{array}$ & 50 dry eye & $\begin{array}{l}\text { Washcloth \& } \\
\text { lid scrubs } \mathrm{n}=25\end{array}$ & Lipiflow $n=25$ & $\begin{array}{l}12 \text { weeks, } 2 x / \text { day } \\
\text { vs single session } \\
\text { Lipiflow }\end{array}$ & $\begin{array}{l}\text { TBUT (at } 4 \text { but not } 12 \text { weeks) in } \\
\text { both groups, Schirmers in the } \\
\text { washcloth group, MG expression } \\
\text { (only examined in Lipiflow } \\
\text { group) }\end{array}$ & $\begin{array}{l}-15.9 \text { from } 52.4 \\
\text { modified } \\
\text { SANDE }\end{array}$ & $\begin{array}{l}\text { Corneal staining, } \\
\text { LLT }\end{array}$ & $\begin{array}{l}\text { Not randomised \& baseline } \\
\text { staining higher in washcloth } \\
\text { group. Lid hygiene encourage } \\
\text { in both group. Duration of } \\
\text { warm compress and frequency } \\
\text { of use not reported }\end{array}$ \\
\hline $\begin{array}{l}\text { Blackie } \\
\text { et al., } \\
2016[22]\end{array}$ & $\begin{array}{l}200 \text { MGD } \\
\text { dry eye }\end{array}$ & $\begin{array}{l}\text { Warm } \\
\text { compress \& lid } \\
\text { hygiene } n=99\end{array}$ & Lipiflow $n=99$ & $\begin{array}{l}12 \text { weeks, } 10 \mathrm{~min} \\
2 \mathrm{x} / \text { day vs single } \\
\text { session Lipiflow }\end{array}$ & $\begin{array}{l}\text { MG expression greater with } \\
\text { Lipiflow }\end{array}$ & $\begin{array}{l}-17.8 \text { from } 51.8 \\
\text { OSDI }\end{array}$ & None reported & $\begin{array}{l}\text { Lipiflow followed for up to } 12 \\
\text { months and positive benefit } \\
\text { still apparent. Baseline OSDI } \\
6.2 \text { points greater in warm } \\
\text { compress group }\end{array}$ \\
\hline $\begin{array}{l}\text { Villani et } \\
\text { al., } 2015 \\
{[23]}\end{array}$ & $50 \mathrm{MGD}$ & $\begin{array}{l}\text { Warm } \\
\text { compress }\end{array}$ & Blephasteam & $\begin{array}{l}3 \text { weeks warm } \\
\text { compress } 10 \text { min } \\
2 \mathrm{x} / \text { day followed } \\
\text { by } 3 \text { weeks } \\
\text { Blephasteam }\end{array}$ & $\begin{array}{l}18 \text { had no improvement in BUT } \\
\text { or acinar diameter with warm } \\
\text { compress, but did with } \\
\text { Blephasteam. No further } \\
\text { improvement in warm compress } \\
\text { responders }\end{array}$ & $\begin{array}{l}-13.6 \text { from } 36.3 \\
\text { OSDI in } \mathrm{n}=32 \\
\text { responders; } \sim- \\
8.7 \text { across all } \\
\text { patients }\end{array}$ & None reported & $\begin{array}{l}\text { Corneal staining, Schirmer * } \\
\text { MG expression in } \\
\text { methodology but not further } \\
\text { reported }\end{array}$ \\
\hline $\begin{array}{l}\text { Bilkhu et } \\
\text { al., } 2014 \\
{[10]}\end{array}$ & 25 MGD & $\begin{array}{l}\text { MDGRx } \\
\text { Eyebag }\end{array}$ & $\begin{array}{l}\text { Contralateral } \\
\text { unheated } \\
\text { MDGRx Eyebag }\end{array}$ & $\begin{array}{l}2 \text { weeks, } 5 \mathrm{~min} \\
2 \mathrm{x} / \text { day followed } \\
\text { for } 6 \text { months }\end{array}$ & $\begin{array}{l}\text { NIBUT, LLT, osmolarity, } \\
\text { MG dropout and expression, } \\
\text { hyperaemia and staining }\end{array}$ & $\begin{array}{l}-33.0 \text { from } 52.5 \\
\text { scaled to } 100\end{array}$ & $\begin{array}{l}\text { Visual acuity \& } \\
\text { corneal } \\
\text { topography }\end{array}$ & $\begin{array}{l}\text { Improvement in OSDI from } \\
\text { day } 1 \text { but continued to improve } \\
\text { daily }\end{array}$ \\
\hline $\begin{array}{l}\text { Lane et } \\
\text { al., } 2012 \\
{[24]}\end{array}$ & 139 MGD & $\begin{array}{l}\text { iHeat warm } \\
\text { compress }\end{array}$ & $\begin{array}{l}\text { Cross-over } \\
\text { Lipiflow }\end{array}$ & $\begin{array}{l}2 \text { weeks, } \\
5 \mathrm{~min} / \text { day }\end{array}$ & $\begin{array}{l}\text { MG expression and TBUT only } \\
\text { with Lipiflow; }\end{array}$ & $\begin{array}{l}-7.8 \text { from } 34.7 \\
\text { OSDI. } \\
\text { Symptom } \\
\text { improvement } \\
\text { greater with } \\
\text { Lipiflow } \\
\end{array}$ & $\begin{array}{l}\text { Staining, IOP, } \\
\text { visual acuity }\end{array}$ & \\
\hline $\begin{array}{l}\text { Matsumo } \\
\text { to et al., } \\
2006 \text { [13] }\end{array}$ & $\begin{array}{l}10 \text { MGD, } 10 \\
\text { controls }\end{array}$ & $\begin{array}{l}\text { Warm moist air } \\
\text { compress }\end{array}$ & Hot towel & $\begin{array}{l}2 \text { weeks, } 10 \mathrm{~min} \\
2 \mathrm{x} / \mathrm{day}\end{array}$ & $\begin{array}{l}\text { LLT (more with warm moist } \\
\text { compress) TBUT (warm moist } \\
\text { compress only) }\end{array}$ & $\begin{array}{l}-53.8 \text { from } 77.3 \\
\text { in ocular fatigue } \\
\text { out of } 100\end{array}$ & Staining & \\
\hline $\begin{array}{l}\text { Mori et } \\
\text { al., } 2003 \\
{[12]}\end{array}$ & $\begin{array}{l}17 \text { MGD, } 8 \\
\text { controls }\end{array}$ & $\begin{array}{l}\text { Eye Warmer } \\
\text { prototype }\end{array}$ & - & $\begin{array}{l}2 \text { weeks, } 5 \text { min } \\
2 x / \text { day }\end{array}$ & BUT, LLT, MG expressability & $\begin{array}{l}-24 \text { from } 52 \\
\text { scaled to } 100\end{array}$ & None reported & \\
\hline
\end{tabular}

